\title{
SOBRE IUSNATURALISMO Y VALIDEZ DEL DERECHO
}

\author{
On Natural Law \\ AND LEgal VALIDITY
}

Sobre JuSNatURALISMO E VALIDADE DO DIREITO

CARLOS I. MASSINI-CORREAS*

* $\quad$ orcid.org/0000-0002-9737-1996. Universidad de Mendoza, Argentina. carlos.massini@um.edu.ar

RECIBIDO: 10 DE JULIO DE 2018. ENVÍO A PARES: 27 DE JULIO DE 2018 APROBAdO POR PARES: O1 DE AGOSTO DE 2018. ACEPTADO: O5 DE SEPTIEMBRE DE 2018

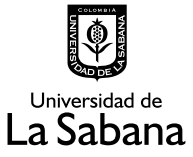

DOI: $10.5294 / D I K A .2019 .28 .1 .1$

PARA CITAR ESTE ARTÍCULO / TO REFERENCE THIS ARTICLE / PARA CITAR ESTE ARTIGO CARLOS I. MASSINI-CORREAS. "SOBRE IUSNATURALISMO Y VALIDEZ DEL DERECHO”, EN 


\section{RESUMEN}

El presente artículo se dirige a repensar y explicitar el relativamente "nuevo" problema de la validez jurídica desde las categorias, los supuestos filosóficos y las definiciones propias de la tradición del iusnaturalismo realista clásico. De este modo se procurará continuar con el desarrollo de esta tradición, ampliándola, corrigiéndola y explicitándola; asimismo, se asumirán y enfrentarán las más recientes objeciones y críticas que se le hayan efectuado desde otros paradigmas filosóficos que brindan una explicación sobre el concepto de validez jurídica.

\section{PALABRAS CLAVE}

Validez jurídica; iusnaturalismo clásico; tradición; iuspositivismo. 


\section{ABSTRACT}

This article aims at rethinking an explaining the quite "new" problem of the legal validity from the categories, philosophical presuppositions and definitions of the Classical Natural Law tradition. Thus, I will try to offer a contribution to the development of that tradition to amplify, amend and explain it. Also, this work will face the many recent challenges that Classical Natural Law tradition has had, like problems and critics coming from other philosophical paradigms, which offer an explanation on the concept of legal validity.

\section{KEYWORDS}

Legal validity; classical natural law; tradition; legal positivism. 


\section{RESUMO}

O presente artigo tem como objetivo repensar e explicitar o relativamente "novo" problema da validade jurídica a partir das categorias, pressupostos filosóficos e definições próprias da tradição do jusnaturalismo realista clássico. Desse modo, procuraremos continuar com o desenvolvimento dessa tradição, além de ampliá-la, corrigi-la e explicitá-la. Igualmente, assumiremos e enfrentaremos as mais recentes objeções e críticas que tenham sido feitas a partir de outros paradigmas filosóficos que apresentam uma explicação sobre o conceito de validade jurídica.

\section{PALAVRAS-CHAVE}

Validade legal; jusnaturalismo clássico; tradição; iuspositivismo. 
SUMARIO: 1. LA CUESTIÓN POR TRATAR. 2. SOBRE LA NOCIÓN GENERAL DE "VALIDEZ" 3. SOBRE LA VALIDEZ DE LAS NORMAS JURÍDICAS. 4. DISCUSIÓN DEL POSITIVISMO. 5. IUSnaturalismo y validez. 6. Algunas precisiones adicionales. 7. Más sobre IUSNATURALISMO Y VALIDEZ: ACOTACIÓN BREVE SOBRE TOMÁS DE AQUiNO. 8. CONCLUSIONES SUMARIAS. BIBIOGRAFÍA.

\section{LA CUESTIÓN POR TRATAR}

Es bien sabido que la problemática de la "validez" del derecho, en especial del derecho normativo, cobró relevancia y difusión recién en el siglo XX, en gran medida por influencia de la obra de Hans Kelsen quien, en su Teoría pura del derecho, desarrolló una doctrina positivista de la validez que tuvo una amplia repercusión en el pensamiento jurídico. ${ }^{1}$ Por su parte, el iusnaturalismo clásico se mantuvo en general alejado de la discusión generada por el concepto de validez jurídica, pues asumió que se trataba de una problemática positivista y que resultaba más productivo centrarse en temas tales como los vinculados a las relaciones entre derecho y moral, la fundamentación del derecho, la cuestión del derecho injusto y otros semejantes. ${ }^{2}$

Ahora bien, en los últimos años ha resurgido la cuestión de la validez de las normas jurídicas a partir de posiciones no positivistas, tal como resulta del planteo efectuado, entre otros, por Robert Alexy, ${ }^{3}$ en el que se introduce la noción de una "validez moral" del derecho que hace referencia, no exclusivamente a las denominadas "fuentes formales" de las normas, sino a los contenidos normativos y a su valoración ética. En un sentido similar se han pronunciado autores de relevancia como Carlos Nino, John Finnis, Rodolfo Vigo, Mark Murphy y Sergio Cotta. ${ }^{4}$ Enmarcándose en esta corriente, en lo que sigue se realizará un estudio breve de lo que puede significar la noción de validez en el contexto de la tradición del iusnaturalismo clásico, y sus consecuencias en el ámbito de la filosofía del derecho contemporánea.

Este enmarcarse en una tradición de pensamiento se explica en cuanto, tal como lo sostiene con precisión Giuseppe Abbà,

... ningún filósofo comienza a pensar desde cero; antes bien se encuentra enfrentado a los problemas filosóficos que le resultan planteados por la lectura que él ha hecho de las obras de otros filósofos [...] Esto, que vale para un filósofo individual, vale también para un conjunto de filósofos que adoptan, en tiempos diversos, la misma figura de filosofia moral elaborada por el fundador de una estirpe o escuela

1 Véase Hans Kelsen, Teoría pura del derecho, México, Porrúa, 1995, pp. 18-37, en especial: 23-28. Véase también Emmanuel PICAVET, Kelsen et Hart. La norme et la conduite, Paris, PUF, 2000, pp. 32 y ss. Asimismo, Brian BIx, Diccionario de teoría jurídica, México D.F., UNAM, 2009, pp. 291-292.

2 Véase en este punto a Giuseppe Graneris, La filosofia del diritto nella sua storia e nei suoi problemi, Roma-Paris-Tournai-New York, Desclée \& C., 1961, passim.

3 Véase Robert Alexy, El concepto y la validez del derecho, Barcelona, Gedisa, 1997, pp. 87 y ss.

4 Por todos, véase Sergio CotTA, Giustificazione e obligatorietà delle norme, Milano, Giufrè Editore, 1981, passim. 
filosófica. Continuando su desarrollo, defendiéndola, corrigiéndola, modificándola bajo la presión de nuevos problemas, de nuevas objeciones, de nuevas críticas, de nuevas figuras, ellos dan vida a lo que se llama una tradición de investigación. ${ }^{5}$

De acuerdo con esta idea, se intentará en lo que sigue repensar y explicitar el relativamente "nuevo" problema de la validez jurídica desde las categorías, los supuestos filosóficos y las definiciones propias de la tradición del iusnaturalismo realista clásico. De este modo se procurará, tal como lo propone Abbà en el párrafo recién citado, continuar con el desarrollo de esta tradición, ampliándola, corrigiéndola y explicitándola; asimismo, se asumirán y enfrentarán las más recientes objeciones y críticas que se le hayan efectuado. De esta manera se estará en presencia de una tradición de pensamiento e investigación viva y operante, que se enriquece y actualiza a la luz de las nuevas ideas y doctrinas, así como de los problemas inéditos que plantean a la inteligencia las circunstancias recientes y nacientes de la existencia humana.

\section{SOBRE LA NOCIÓN GENERAL DE "VALIDEZ"}

En general, se entiende por validez "la existencia justificada de algo, distinguiéndola del existir o ser pensado únicamente de hecho"; debe agregarse que "la validez no se atribuye tanto a las cosas [o estados de cosas] cuanto a los productos del pensamiento, como conceptos, juicios, raciocinios, ciencia o, en el dominio práctico, a normas o leyes. [La validez] apunta por encima de ellos [proposiciones teóricas, normas] a un fundamento que los trasciende". ${ }^{6}$ De aquí se sigue que, en principio, lo "válido" hace referencia a aquello que resulta justificado racionalmente, sea desde la perspectiva lógica, técnica, epistémica o práctica (moral, jurídica, politica, etc.); en este sentido, una inferencia lógica será válida si su ilatividad está justificada por las reglas de la lógica, una regla técnica lo será si sigue las reglas generales del arte que corresponda, una proposición científica resultará válida si está debidamente demostrada, y una proposición normativa lo será si se encuentra justificada deónticamente. Esto se confirma con la etimología de la palabra, que proviene del latín validus, que significa "fuerte", "vigoroso", "que tiene valor”, es decir, con fuerza epistémica, lógica, ética, etc., y que se incorporó al idioma castellano recién en el siglo XVII. ${ }^{7}$ De esto se sigue que la palabra y la noción de validez revisten carácter analógico, esto es, se refieren a realidades diversas vinculadas por relaciones de diferente especie, pero que guardan, a pesar de estas diferencias, una cierta unidad de significado. ${ }^{8}$ Se volverá sobre esto más adelante.

5 Giuseppe AввÀ, Quale impostazione per la filosofia morale?, Roma, LAS, 1996, p. 27. Véase también Pedro Serna, Filosofia del derecho y paradigmas epistemológicos, México, Porrúa, 2006, pp. 1-5.

6 Jan de Vries, Voz "Validez", en Diccionario de filosofia, dir. W. Brugger, Barcelona, Herder, 1975, pp. 523-524. Véase también, Diccionario de filosofia, dir. José Ferrater Mora, Madrid, Alianza, 1979, pp. 3371-3372. posicional, a la verdad subjetiva y la de rectitud normativa (Jürgen HaBERMAS, Facticidad y validez, Madrid, Trotta, 1998, p. 78). 
Ahora bien, del mismo modo que las actividades del entendimiento (conceptos, juicios, razonamientos) se distinguen principalmente en especulativas y prácticas, la validez de las creaciones de ese mismo entendimiento: proposiciones especulativas o prácticas, puede dividirse en especulativa y práctica. ${ }^{9}$ Una validez será especulativa cuando se trate de validar una proposición de ese tipo, como las científico-empiriológicas, o simplemente descriptivas, y será práctica, cuando se pretenda validar proposiciones de carácter práctico, ${ }^{10}$ como las que corresponden a las normas jurídicas, como cuando se establece que los padres deben alimentar a sus hijos menores o que se ha de detener el automóvil ante un semáforo en rojo.

Y si se circunscribe ahora el estudio a la validez práctico-normativa, que es la que aquí interesa en definitiva, resulta conveniente efectuar algunas aclaraciones preliminares: i) el orden práctico-normativo abarca -entre otras realidades-aquellas proposiciones directivas de la acción humana, que también pueden denominarse "deónticas"11 (en sentido amplio) y que se distinguen según los diferentes modos de dirección de la conducta, entendida esta como acción humana deliberada y electiva; existen, por lo tanto, proposiciones prescriptivas, prohibitivas y permisivas, para citar solo las modalidades deónticas principales; ${ }^{12}$ ii) estas proposiciones aportan razones decisivas para la acción, es decir, "determinan lo que es racional para nosotros realizar cuando, en virtud de una o más de ellas, tenemos razones adecuadas (normativas) para una acción, como cuando tenemos una razón práctica para realizar algo y no una razón para no hacerlo"; ${ }^{13}$ estas razones para la acción radican en definitiva en ciertos bienes humanos, cuya búsqueda de realización es la que otorga sentido normativo a la dirección de la conducta; ${ }^{14}$ iii) de lo anterior se sigue que la dirección de la acción humana reviste un carácter eminentemente racional; tal como lo precisa Mark Murphy, "los únicos estándares que pueden inducir a los seres racionales y en cuanto seres racionales a la acción son estándares racionales. Por lo tanto, el derecho [normativo] es un estándar racional de la conducta"; ${ }^{15}$ iv) de lo precisado hasta ahora se desprende que la validez de las normas -incluidas las jurídicas pero no solo ellas-, es decir, su justificación en cuanto tales, debe consistir en una fundamentación o validación racional; pero además, esta justificación ha de revestir carácter racional-práctico (o "deóntico") de modo tal que alcance a justificar proposiciones prácticas, habida cuenta de que de meras proposiciones descriptivas de hechos o estados de

9 Acerca de esta distinción, véase Yves Simon, Practical Knowledge, ed. R. J. Mulvaney, New York, Fordham University Press, 1991, passim.

10 Sobre el concepto de razón práctica, véase Georges Kalinowski, Initiation à la philosophie morale, Paris, Societé d'Éditions Internationales, 1966, pp. 183 ss.

11 Acerca del origen del término “deóntico”, véase José Ferrater Mora, op. cit., pp. 745-749. Del mismo modo, véase Georges Kalinowski, Lógica del discurso normativo, Madrid, Tecnos, 1975, pp. 15-68.

12 Véase Georges Kalinowski, La logique déductive. Essai de présentation aux juristes, Paris, PUF, 1996, pp. 101-159.

13 Robert Audi, Reasons, Rights, and Values, Cambridge, Cambridge University Press, 2015, p. 15.

14 Véase, en este punto, John Finnis, Natural Law and Natural Rights, Oxford, Oxford University Press, 2011, pp. 118-125.

15 Mark MurpHy, Philosophy of Law. The Fundamentals, Oxford-Malden-Carlton, Blackwell, 2007, p. 39. 
cosas no puede seguirse lógicamente la justificación de proposiciones prácticas, como las jurídicas. ${ }^{16}$

Dando por supuesto lo anterior, es posible sostener que, en el caso de las normas jurídicas, puede denominarse "validez jurídica" a su carácter obligatorio racionalmente justificado. O, en otras palabras, su "validez" se identifica con la existencia de las normas en cuanto exigibles fundadamente y generadoras de razones decisivas para la acción. En un sentido similar, Joseph Raz sostiene que "una regla que no es jurídicamente válida no es definitivamente una regla jurídica”, y que "el mejor camino para la comprensión de 'jurídicamente válido' es atendiendo al hecho de que es usada intercambiablemente con 'jurídicamente vinculante' (binding)" ${ }^{17} \mathrm{O}$ en otras palabras: la existencia deóntica de las normas depende de una justificación, valga la redundancia, de carácter deóntico y esta justificación no puede ser sino racional. ${ }^{18}$

Pero en este punto corresponde agregar, para mayor precisión, que las normas son una realidad de carácter intencional, ${ }^{19}$ es decir, no una realidad meramente fáctica o lingüistica (aunque se expresen mediante el lenguaje) sino esencialmente cognitiva ${ }^{20}$ o, como dice Millán-Puelles, simplemente objetual, con "objetualidad pura práctica" ${ }^{21}$ No pueden por lo tanto confundirse ni i) con las realidades deónticas en las que se fundamentan, ni ii) con los juicios-actos psicológicos que les dan origen y los ponen en la existencia ni iii) con los signos lingüísticos en los que se expresan, se determinan y se fijan. Se trata, por lo tanto, para seguir con la terminología clásica, de "entes de razón con fundamento in re", es decir, de entidades "intencionales", como los llama Roman Ingarden, ${ }^{22}$ o bien entidades cognitivas, cuya existencia concreta injiere accidentalmente en los correspondientes actos psicológicos del sujeto que las conoce. ${ }^{23} \mathrm{Y}$ es casualmente ese carácter intencional-cognitivo que revisten las normas lo que hace necesaria su validación, es decir, un razonamiento de justificación que las fundamente racionalmente y las ponga en la existencia en cuanto normas.

16 Véase Carlos Ignacio MAssinI-CoRreAs, La falacia de la "falacia naturalista", Mendoza, EDIUM, 1995, passim.

17 Joseph RAz, "Legal validity", en The Authority of Law. Essays on Law and Morality, Oxford, Clarendon Press, 1997, pp. 146-149.

18 Conviene destacar aquí que varios autores iuspositivistas distinguen decisivamente entre la validez del derecho y su obligatoriedad, y reducen el problema de la validez al de la inclusión lógica en el sistema jurídico, y remiten el segundo al de la provisión de razones para el obrar o de la normatividad juridica (Andrei Marmor, Philosophy of law, Princeton-Oxford, Princeton University Press, 2011, pp. 1-7). En un sentido similar piensa Eugenio Buligyn (El positivismo jurídico, México, Fontamara, 2006, pp. 96 y passim). Esto resulta impensable desde una perspectiva iusnaturalista, ya que para esta perspectiva la inclusión en el sistema jurídico incluye dimensiones normativas o de provisión de razones para la acción, tal como se verá más adelante.

19 Sobre la noción de intencionalidad, véase Alejandro Llano, Teoría del conocimiento, Madrid, BAC, 2015, pp. 5-20.

20 Véase Georges KalinowsKI, "Essai sur le caractère ontique du droit. Contribution à l'être intentionnel et à l'ontologie du droit”, en Revue de l'Université d'Otawa V-34 (1964), pp. 81-99.

21 Véase Antonio Millán-Puelles, Teoría del objeto puro, Madrid, Rialp, 1990, pp. 829 y ss.

1422 Véase Roman Ingarden, Sobre la responsabilidad. Sus fundamentos ónticos, trad. J. M. Palacios, Madrid, Caparrós, 2001, passim.

23 Sobre esto, véase Carlos Ignacio Massini-Correas, Filosofia del derecho. I. El derecho, los derechos humanos y el derecho natural, Buenos Aires, LexisNexis/Abeledo Perrot, 2005, pp. 52-59. 


\section{SOBRE LA VALIDEZ DE LAS NORMAS JURÍDICAS}

Ahora bien, si se concentra el estudio solo en la problemática de la validez jurídica, más concretamente en la correspondiente a las normas jurídicas, ${ }^{24}$ corresponde simplificar la cuestión brevitatis causa y reducir las soluciones a las dos principales que se han propuesto en los debates del pensamiento jurídico: la solución positivista y la iusnaturalista. En este punto, Andrei Marmor realiza un buen análisis de la cuestión en un artículo publicado -junto con Alexander Sarch- en la Stanford Encyclopedia of Philosophy con el titulo "The nature of law". ${ }^{25}$ En ese lugar, bajo el acápite "The conditions of legal validity", y comenzando con la propuesta del positivismo jurídico, estos autores sostienen que "la mayor intuición del positivismo jurídico, de que las condiciones de la validez jurídica están determinadas por hechos sociales, implica dos afirmaciones separadas, que han sido calificadas como la 'tesis social' y la ‘tesis de la separación””, ${ }^{26}$

Según la primera tesis, el derecho normativo ${ }^{27}$ es, en su más estricta acepción, un fenómeno social y, por lo tanto, las condiciones de su validez no consisten en justificaciones normativas sino en meros hechos sociales. Sostienen Marmor y Sarch que "un modo de entender la posición del positivismo jurídico en este punto es el de verlo como un modo de reducción: los positivistas jurídicos sostienen, esencialmente, que la validez jurídica es reductible a hechos de tipo no normativo, es decir, hechos acerca de la conducta, creencias y actitudes de la gente". ${ }^{28}$ Según la segunda tesis, que es una implicancia de la primera, existe una separación conceptual entre derecho y moral, es decir, entre lo que el derecho es y lo que debería ser. En este punto, escriben Marmor y Sarch que "la tesis de la separación, entendida con propiedad, corresponde solo a las condiciones de la validez jurídica. Ella afirma que las condiciones de la validez jurídica no dependen del mérito moral de las normas en cuestión”. ${ }^{29}$

Pasando ahora a la propuesta de las teorias del derecho natural, los autores citados comienzan por sostener que los iusnaturalistas niegan la afirmación central del positivismo jurídico,

... insistiendo que una norma reputada como tal no llega a ser jurídicamente válida salvo que pase un cierto umbral de moralidad. El derecho positivo ha de conformarse en su contenido a ciertos principios básicos del derecho natural, es decir, de la mo-

24 Sobre la noción y estructura de las normas, véase Georges KaLINowski, Logique des normes, Paris, PUF, 1972, passim.

25 Andrei MARmor y Alexander SARCh, "The nature of law", Stanford Encyclopedia of Philosophy, Fall 2015 Edition, ed. Edward N. ZALTA, en https://plato.stanford.edu/archives/fall2015/entries/ lawphil-nature/

26 MARMOR y SARCH, "The Nature of Law", op. cit., p. 2.

27 En el presente contexto se denomina "derecho normativo" al conjunto sistemático de normasproposiciones normativas de carácter jurídico, en oposición a otras significaciones análogas de "derecho", como el derecho-conducta, el derecho subjetivo, el derecho-ciencia, etc. Véase Massini-Correas, Filosofia del derecho. I. El derecho, los derechos humanos y el derecho natural, op. cit., pp. 38-49.

28 MARMOR y SARCH, "The Nature of Law", op. cit.

29 Ibid., p. 3. 
ralidad universal, en orden a devenir derecho en primer lugar. En otras palabras, los iusnaturalistas mantienen que el contenido moral o mérito de las normas, y no solo sus origenes sociales, forman también parte de las condiciones de validez jurídica. ${ }^{30}$

También aceptan estos autores que el iusnaturalismo es una concepción no reductiva del derecho, ya que defiende que la validez juridica no puede ser reducida meramente a hechos no normativos.

Finalmente, Marmor y Sarch reconocen que "la tradición de la ley natural ha experimentado un considerable refinamiento a lo largo del siglo $\mathrm{XX}$, principalmente porque su versión clásica y más popular se enfrenta a una objeción obvia a su intuición central: es muy dificil de mantener que una ley moralmente mala no es un ley". ${ }^{31}$ Como ejemplo de este refinamiento, estos autores se refieren a la posición de John Finnis, quien "ve al derecho natural (en su versión tomista), no como una exigencia sobre la validez jurídica de las normas positivas, sino principalmente como la elucidación de un ideal del derecho en su sentido pleno o más elevado, concentrándose en las maneras en que el derecho necesariamente promueve el bien común". ${ }^{32}$ Estos autores también ponen como arquetipo de la posición iusnaturalista a la obra de Ronald Dworkin, en sus diferentes etapas, y la discuten en sus principales afirmaciones; este debate se dejará de lado, fundamentalmente por razones de brevedad y de simplicidad de las argumentaciones.

\section{Discusión DEL POSITIVISMO}

Expuestas brevemente -con la colaboración de Marmor y Sarch- las dos principales posiciones en lo que se refiere al concepto y los alcances de la validez jurídica de las normas de derecho, conviene efectuar algunas consideraciones sobre cada una de ellas, para concentrarse luego con más detalle en la que pertenece al realismo clásico. ${ }^{33}$ Comenzando por la concepción positivista, corresponde destacar ante todo su reduccionismo constitutivo, es decir, la pretensión de explicar exhaustivamente un ámbito de la realidad, en este caso el derecho normativo, con el exclusivo recurso a uno y solo uno de sus elementos componentes. ${ }^{34}$ En efecto, si bien resulta indudable que, en virtud de su carácter eminentemente social, el derecho está integrado también por realidades y dimensiones fáctico-sociales, como

30 Ibid., p. 2. Véase, en este mismo sentido, John Gardner, "Legal Positivism: 5 1/2 Myths", en American Journal of Jurisprudence 46 (1) (2001), pp. 199-227.

31 MARMOR y SARCH, "The Nature of Law", op. cit., p. 3.

32 Ibid.

33 Como exposición preliminar de esta última concepción, véase Carlos Ignacio MASSINI-CORREAS, "La máxima 'lex injusta non est lex' y algunas opiniones contemporáneas”, en AA.VV., In umbra intelligentiae. Estudios en homenaje al Prof. Juan Cruz Cruz, ed. A. L. González y M. I. Zorroza, Pamplona, EUNSA, 2011, pp. 587-604.

34 Sobre la noción de reduccionismo, véase Carlos Ignacio MAssinI-CoRREAS, "Riduzionizmo, fatti sociali e normatività del diritto”, en Rivista di filosofia del diritto 1 (2013), pp. 227-244. Asimismo, véase Fernando IncIarte, Eindeutigkeit und Variation. Phänomene und das Problem des Reduktionismus, Freiburg, Alber, 1973, passim; y Carlos Ignacio Massini-CorREas, "Entre reductivismo y analogia. Sobre el punto de partida de la filosofia del derecho", en Persona \& Derecho 66-67 (2012), pp. 353-385. 
actos de coacción pública, publicidad de las resoluciones, regulación de acciones en alteridad, coordinación de actividades humanas, etc., resulta claro que el derecho no se reduce meramente a esas dimensiones y actividades, sino que incluye inexorablemente razonamientos, valoraciones, deliberaciones, mandatos y varias más, cuya naturaleza aparece claramente como racional y valorativa, es decir, como de indole estrictamente intelectual-moral.

El principal problema que se plantea a todos los intentos reduccionistas es que la pretensión de alcanzar una explicación íntegra o exhaustiva de un sector de la realidad a través de la remisión a solo uno de sus varios elementos está condenada de antemano al fracaso, ya que con ese intento de justificación solo se puede alcanzar una explicación parcial o sesgada. Y esto en razón de que, como sostiene Soaje Ramos,

... a no ser en virtud de un prejuicio, no se puede decidir tampoco desde el punto de partida de la indagación que el derecho que es asunto de la iusfilosofia, es exclusivamente el derecho positivo [...]. Tal decisión no se compadece con la integralidad de la experiencia jurídica y prima facie resulta arbitraria. ${ }^{35}$

Y resulta arbitraria, en especial, por tratarse del objeto de la filosofia, en este caso de la filosofia del derecho, que por definición intenta una explicación integral, universal y en términos de raíces.

Es cierto que en algunas ciencias puede llevarse adelante una explicación de tipo reductivo, ${ }^{36}$ es decir que priorice una perspectiva o un aspecto de la realidad estudiada, como cuando se estudian los aspectos químicos de los actos psicológicos, pero esta explicación resulta inexorablemente parcial y fragmentaria, y debe ser reconocida como tal sin negar la posibilidad de abordar el estudio desde otras perspectivas o con otros métodos. ${ }^{37}$ Pero en el caso de la filosofia, cuya pretensión radical consiste en proponer una elucidación integral desde la perspectiva más fundamental o de principios, el recurso al reduccionismo aparece como claramente inadecuado y, en definitiva, deformante. Étienne Gilson defiende que el reduccionismo es una tentación perenne del pensamiento filosófico, que aparece en todas las épocas de ese pensamiento, que lo limita y desfigura, y que solo puede ser superado por el recurso a la analogia de los conceptos, en especial del concepto trascendental de ser, que hace posible la comprensión de la realidad completa desde diferentes dimensiones analógicas. ${ }^{38}$

35 Guido SOAJE RAmos, "Sobre derecho y derecho natural. Algunas observaciones epistemo-metodológicas", en Ethos 6/7 (1979), p. 101.

36 Sobre los diversos significados de "reductivo", véase Józef María Bochenski, Los métodos actuales del pensamiento, Madrid, Rialp, 1979, pp. 183 y ss.

37 Evandro AGAzzI, “Analogicità del concetto di scienza. Il problema del rigore e dell'oggettività nelle scienze humane”, en AA.VV., Epistemologia e scienze umane, ed. V. Possenti, Milano, Massimo, 1979, pp. 57-95.

38 Véase Étienne Gilson, La unidad de la experiencia filosófica, Madrid, Rialp, 2004, pp. 257 y ss. Sobre el papel de la analogía en el pensamiento jurídico, véase Carlos Ignacio MASSINI-CoRREAS, "Sobre ciencia práctica y prudentia. Aproximaciones desde las ideas de John Finnis", en Sapientia 227-228 (2010), pp. 41-53. 
Pero además de la radical debilidad del reduccionismo, en el positivismo aparece otra deficiencia aún mayor, y es la que corresponde a la pretensión de fundar una realidad de carácter indudablemente deóntica, como lo es el derecho normativo, en un conjunto de meros hechos sociales. En este punto, John Finnis sostiene que, para el positivismo, "todo el derecho está basado-en-fuentes. Una norma jurídica está basada en fuentes si su existencia y contenido puede ser identificado solo por referencia a hechos sociales, sin recurrir a ningún argumento valorativo". Y más adelante, el profesor australiano opone a esta afirmación un argumento fundamental:

... nadie puede nunca racionalmente tratar un mero hecho como dando razón para algo, y mucho menos para algo tan demandante y restrictivo de las elecciones como el derecho. Ha de haber siempre algún "argumento valorativo" para tratar algún hecho o combinación de hechos como la "base" para identificar una proposición como impositiva de una obligación, o como de algún modo directiva o normativa. ${ }^{39}$

Dicho en otras palabras: una posición positivista consecuente caerá inexorablemente en las redes de la denominada "ley de Hume", según la cual resulta imposible lógicamente inferir proposiciones normativas a partir de meras proposiciones descriptivas o asertivas de hechos, sean estos sociales o no. ${ }^{40}$ Esta regla lógica ha sido objeto de enconados debates y utilizada abusivamente por varios positivistas como argumento, presuntamente decisivo, contra toda forma de iusnaturalismo. ${ }^{41}$ Pero sucede que, teniendo en cuenta todos los aspectos de la cuestión, esa regla se vuelve fatalmente contra los mismos positivistas, y su pretensión de validar normas (proposiciones normativas) solo desde hechos sociales (proposiciones descriptivas), termina por ser falaz y descalificadora.

No obstante lo anterior, algunos de quienes aparecen como los positivistas más rigurosos de este tiempo, Joseph Raz y Andrei Marmor, han intentado superar esa objeción, proponiendo una doctrina que, a la vez que asume la tesis de las fuentes sociales, no incurra en la falacia ser-deber ser. Esta doctrina radica en introducir la noción de "autoridad" como mediadora entre los simples hechos sociales y las normas jurídicas resultantes, pretendiendo que la mediación de ese elemento autoritativo proporciona al argumento de validación la cuota de deonticidad que resulta estrictamente necesaria.

En su libro Philosophy of Law, Marmor resume esta posición sosteniendo en primer lugar que "el derecho necesariamente exige revestir una autoridad legitima [...] [y] hariamos lo mejor explicando la normatividad del derecho apuntando al hecho de

39 John Finnis, "Introduction", en Collected Essays: Volume IV. Philosophy of Law, Oxford, Oxford University Press, 2011, pp. 3-4.

40 Acerca de los alcances de esta "ley", véase AA.VV., The Is-Ought Question, ed. D. Hudson, London, MacMillan, 1969, passim.

1841 En este punto, véase, entre muchos otros, Ernesto GARZón VALDÉs, Derecho y "naturaleza de las cosas". Análisis de una nueva versión del derecho natural en el pensamiento jurídico alemán contemporáneo, vol. II, Córdoba-Argentina, Universidad Nacional de Córdoba, 1971, pp. 86 y passim. 
que la gente tiende a ver los requerimientos jurídicos como vinculantes"; y más adelante agrega que "lo que convierte en únicas a las instrucciones autoritativas, no es que ellas generen razones identificadas por la identidad [de la autoridad], aunque también hagan esto necesariamente, sino el hecho de que esas razones sean de naturaleza obligatoria”. ${ }^{42}$ Ahora bien, estas normas autoritativas defendidas por Marmor como supuestamente obligatorias, emanan de una autoridad que es establecida por hechos sociales, con lo cual la facticidad de los fundamentos de las normas se desplaza un poco más atrás pero no desaparece. Escribe Marmor que "en cuanto podamos mostrar que 1) el derecho siempre consiste en directivas autoritativas, y que 2) la cuestión de quién cuenta como autoridad jurídica y cómo esa autoridad ha de ser ejercida está determinada por reglas sociales, hemos establecido los fundamentos para una reducción de la juridicidad a hechos de carácter no normativo" ${ }^{43}$

Pero resulta innegable que este intento de justificar la validez del derecho a partir de hechos sociales que establecen una autoridad, la que a su vez es la fuente de las normas jurídicas, incurre igualmente en la falacia ser-deber ser y que, por lo tanto, existe un non sequitur que impide que la juridicidad de esas normas resulte validada. No pueden quedar dudas de que a partir meramente de afirmaciones tales como "la autoridad A ha sido aceptada por el consenso X en la comunidad C", no puede inferirse que "las normas sancionadas por A revisten validez jurídica (y por tanto deben ser obedecidas) en la comunidad C", todo ello sin que medie una proposición deóntica mediante la cual se justifique que "las normas sancionadas por A son jurídicamente válidas (obligatorias)”. ${ }^{4}$

En definitiva, el dilema al que se aboca esta cuestión radica en que es
... necesario realizar una opción inexcusable: o bien i) se acepta que el derecho re- viste carácter normativo y por lo tanto provee razones no meramente hipotéticas para la acción y entonces se debe abandonar la pretensión del carácter solamente empírico de su justificación racional, o bien ii) se reafirma el carácter estricta- mente empírico de la justificación y explicación del derecho (y la consiguiente indole descriptiva de todo conocimiento jurídico) y, consecuentemente, se sacri- fica el carácter normativo y de proveedor de razones para la acción atribuido por principio al derecho. ${ }^{45}$

Pero la última de estas opciones conducirá necesariamente a una incomprensión de lo jurídico en cuanto tal, por lo que convendrá explorar brevemente la respuesta de su alternativa iusnaturalista.

\footnotetext{
42 Andrei Marmor, Philosophy of Law, op. cit., pp. 60-63. Véase también Joseph Raz, "Legitimate Authority", en The Authority of Law, op. cit., pp. 3-27.

43 Andrei Marmor, Philosophy of Law, op. cit., p. 73, 77-83.

44 En este punto véase Carlos Ignacio Massins-Correas, Facticidad y razón en el Derecho. Análisis crítico de la iusfilosofia contemporánea, Buenos Aires, Marcial Pons, 2015, pp. 37-49. 


\section{IUSNATURALISMO Y VALIDEZ}

En el caso del iusnaturalismo, tal como se explicó al comienzo siguiendo las afirmaciones de Andrei Marmor, la cuestión de la validez y consiguiente obligatoriedad de las normas jurídicas reviste también una exigencia de contenido: que sus directivas han de ordenarse a la coordinación de las conductas sociales de los miembros de una comunidad política para orientarlas al bien humano común. ${ }^{46}$ En otras palabras, desde la perspectiva del iusnaturalismo clásico, para que una norma tenga validez jurídica y resulte por lo tanto obligatoria, son necesarias dos cosas: i) que haya sido producida por alguna fuente institucional de normas (legislación, fallos judiciales, costumbre jurídica, actos jurídicos o administrativos, etc.), y ii) que sus contenidos sigan y respeten las exigencias de contenido que se mencionaron más arriba.

De esta manera, es claro que si bien para el positivismo -que intenta ver el derecho "desde fuera"- las que importan realmente son las fuentes institucionales o sociales, aunque en alguna de sus versiones (v. gr. los positivismos denominados "incluyentes") se prevea la posibilidad de que, contingentemente, se incluyan algunas exigencias morales en el test de validez, ${ }^{47}$ para la Teoría de la Ley Natural -cuya intención epistémica es conocer al derecho no solo desde fuera sino también "desde dentro"- las que realmente importan en definitiva son las razones morales de justificación. En otras palabras, esto significa que para el positivismo el derecho normativo se conoce solo a partir de su manifestación en la experiencia juridica fáctica, aunque sin trascenderla y centrarse en las razones para la acción o razones de obligación y en su fundamento, como lo hace claramente el iusnaturalismo.

En realidad, para este último puede distinguirse con precisión entre: i) una validez jurídica "formal", "social" o "institucional" (VS), que proviene de las distintas fuentes de manifestación, emisión o presentación de las normas jurídicas, y ii) una validez "material", "racional" o "moral" (VR), que proviene del valor moral de los contenidos de las normas y que, a la inversa de la validez formal, puede tener una intensidad mayor o menor; es decir, desde esta perspectiva, la validez de las normas puede ser más o menos significativa y tener distintas consecuencias en la vida jurídica. Ahora bien, desde el punto de vista de la experiencia jurídica o del conocimiento jurídico, es claro que la que primero aparece a la percepción es la validez formal (leyes, decretos, fallos judiciales, costumbres reconocidas, actos jurídicos, etc.); además, es la más sencilla de verificar en los hechos: v. gr. una ley es válida formalmente -entre otras exigencias- si ha sido publicada por la autoridad competente.

46 Véase John Finnis, Natural Law and Natural Rights, 2 ed., Oxford, Oxford University Press, 2011, pp. 154-156 y passim; véase también, del mismo autor, "Law as coordination", en Collected Es-

2047 says. Volume IV. Philosophy of Law, op. cit., pp. 66-73. co. Estudios criticos sobre el Inclusive Legal Positivism, eds. J. B. Etcheverry y P. Serna, Granada, Comares, 2010, passim. 
Por su parte, la validez moral es el objeto y la consecuencia de un proceso ulterior, de análisis crítico y debate dialéctico entre los sujetos de las normas acerca del valor moral de los resultados de su aplicación. Pero, en rigor, esta validez moral, si bien es ulterior en el proceso cognitivo es, desde el punto de vista deóntico, la decisiva, la que en última e irrevocable instancia determina si una determinada norma jurídica (y, en casos excepcionales, un sistema jurídico completo) ${ }^{48}$ tiene validez y, consecuentemente, resulta obligatoria. Puede hablarse, por lo tanto, de una validez jurídica prima facie, la formal-social-institucional (VS), y de otra definitiva, básica o decisiva, la moral-racional-material (VR), que es la que en última instancia determina de modo definitivo la validez de las normas jurídicas.

En un sentido similar, John Finnis ha escrito, en un valioso ensayo publicado en la Stanford Encyclopedia of Philosophy, que, prima facie, las normas positivas están dotadas de una validez autoritativa independiente de su contenido normativo, pero

\begin{abstract}
... esta independencia de contenido de las razones autoritativas implica su obligatoriedad [solo] presuntiva. La capacidad de ser desplazada o anulada (defeasible) que reviste esta presunción, está implicada en la dependencia de la fuerza perentoria, preferente o excluyente de esas razones autoritativas respecto de un trasfondo presupuesto de bienes y necesidades humanas básicas y de principios y normas morales básicos, un trasfondo que supone que si una razón autoritativamente proferida (positiva) entra en conflicto suficientemente claro con esas necesidades, bienes, principios o normas permanentes, su fuerza exclusionaria deviene exhausta o superada, y las obligaciones positivas resultan derrotadas (defeated). ${ }^{49}$
\end{abstract}

Esto significa que, para Finnis, a quien se sigue en este punto, estos principios y normas morales que derrotan en ciertos casos a las normas provenientes de fuentes sociales autoritativas, son promotoras de validez jurídica, es decir, son propia y específicamente "fuentes de derecho válido" y, por lo tanto, generan obligaciones jurídicas. Esto en razón de que "cualquier norma o principio que un tribunal está obligado o autorizado a aplicar, precisamente como tribunal, puede razonablemente ser reconocido y contar como derecho, es decir, como norma o principio que ha de ser considerado como parte de nuestro derecho", ${ }^{50}$ en otras palabras, como derecho válido u obligatorio jurídicamente. Y es por ello que el mismo Finnis considera que si el contexto discursivo en el que se argumenta está centrado en esa obligatoriedad de las normas, "se puede decir que la norma [injusta], a despecho de sus vínculos con fuentes social-fácticas, no solo es moralmente no directiva, sino también jurídicamente inválida". ${ }^{51}$ Dicho brevemente: a todos los efectos prácticos, no se trataría propiamente de "derecho válido".

48 En este punto, véase Robert AlExy, El concepto y la validez del derecho, op. cit., pp. 87 y ss.

49 John FinNis, "Natural law theories", en Stanford Ecyclopedia of Philosophy, Fall 2011 Edition, ed. Edward N. Zalta, en http://plato.stanford.edu/entries/natural-law-theories/, p. 15 (énfasis agregado).

$50 \quad$ Ibid., p. 17.

51 Ibid., p. 22. 
De aquí se sigue que, considerados todos los aspectos estudiados, puede decirse fundadamente que el "caso central" y la "significación focal"52 de "validez jurídica" es la que corresponde a la que se ha denominado "validez material-racional-moral” (VR). Esto es así al menos en cuanto se considera la cuestión desde el punto de vista de la racionalidad práctica, deóntica o práctico-normativa. En sentido inverso, si se aborda la cuestión desde un punto de vista empírico-experiencial, podría afirmarse que la acepción primera de "validez jurídica" es la formal-social. Pero en rigor, es necesario considerar que esta última forma de validez no es sino la manifestación, expresión, determinación y formalización externa de la validez en su caso central, que no puede ser otra que la VR.

Dicho en otras palabras: no se trata aquí de que las normas válidas desde la perspectiva formal-social revistan la validez propiamente "jurídica", y releguen a la denominada material-moral al desván de los recursos "extrajurídicos", ocasionales, contingentes y supletorios. Por el contrario, si se aborda la cuestión de la validez jurídica desde el punto de vista propio de la filosofia y la ciencia jurídica, es decir, el punto de vista práctico-normativo o deóntico, ${ }^{53}$ la validez jurídica es principal y decisivamente material-racional-moral y solo presuntiva, prima facie, y provisoriamente formal-institucional-social. Dicho de otro modo: la significación focal y el caso central de "validez jurídica" es el de la validez material-racionalmoral (VR), con lo que la validez formal-institucional-social (VS) queda relegada a un caso periférico y una significación derivada o analógica, lo que no significa que no posea también una dimensión racional. Sobre esto último se realizarán más adelante algunas consideraciones.

\section{Algunas precisiones adicionales}

De lo dicho precedentemente surge con claridad que, en el caso de la validez jurídica, se está en presencia de un concepto y de un término analógicos, es decir, de conceptos y términos que hacen referencia a realidades diversas, pero que tienen una cierta similitud significativa y estructural, ya sea porque las cosas designadas participan de una misma realidad o porque tienen una ratio proporcional semejante. En este punto, Ralph McInerny escribe: "se dice que ciertas cosas son nombradas analógicamente cuando, aunque tengan un nombre en común, las definiciones [conceptos] que corresponden al nombre son en parte iguales y en parte diferentes, y una de estas definiciones resulta preferente a las restantes". ${ }^{54}$

En el caso que aquí interesa es posible hablar de "validez jurídica" en varios sentidos analógicos, principalmente en dos: la validez social (VS) y la racional (VR), y en ambos casos se significa la justificación práctico-racional de una proposición

52 Véase, acerca del significado de estas expresiones, John FinNis, Natural Law and Natural Rights, op. cit., pp. 9-11.

53 Véase Carlos Ignacio Massini ConReAs, Filosofia del derecho. III. El conocimiento y la interpretación jurídica, Buenos Aires, Abeledo-Perrot, 2008, pp. 27-60.

54 Ralph McInerny, Aquinas and Analogy, Washington D.C., The Catholic University of America Press, 1996, p. 96. 
normativa, aunque esas formas de justificación no sean idénticas sino semejantes: en ambos casos se trata del fundamento del carácter jurídico-obligatorio de las normas jurídicas, si bien uno de estos fundamentos es predominantemente formal-social y proviene del origen o la fuente de las normas, y el otro es racionalmoral y radica en la adecuación (mayor o menor) del contenido de las normas a los principios y las reglas morales pertinentes. ${ }^{55}$

Pero resulta conveniente aclarar que, en ambos casos, se trata de una justificación de carácter racional-práctico, toda vez que en el primero la justificación proviene de la autoridad del gobernante, cuya legitimidad se funda en definitiva en su ordenación al bien común político, es decir, en una exigencia de carácter moral, y en el segundo más directamente en la congruencia entre la directiva normativa y los principios o las normas moral-sociales (de moral crítica, no meramente fáctica) que orientan la conducta hacia el bien humano en comunidad. En este último caso, la relación con la racionalidad práctico-moral es más directa, razón por la cual puede hablarse aquí de una validez analógicamente focal, o de un caso central de validez, o bien de validez en sentido propio y principal; y como consecuencia, en el caso de la validez formal-social se estará en presencia de un caso derivado o colateral de validez. Pero en ambos casos, se estará frente a una relación proporcional entre las normas y su justificación racional, relación que es la que proporciona a la noción de validez su unidad analógica. ${ }^{56}$

Esto significa que, aun en el caso de la VS, en ella existe una dimensión racional, más concretamente de racionalidad práctico-moral, y que no se trata, por tanto, de una mera facticidad o socialidad exterior. Y esto es así toda vez que la existencia de las denominadas "fuentes sociales" supone, para que se trate en efecto de "fuentes", el cumplimiento de ciertos requisitos que se vinculan de manera estructural con la "racionalidad procedimental" de que habla Vigo en un artículo reciente. ${ }^{57}$ Entre estos requisitos se encuentran algunos de los ocho desiderata que enumera Fuller en su conocido The Morality of Law, entre ellos el de publicidad, ya que las normas que no son publicadas carecen de validez; el de no contradictoriedad, porque es evidente que múltiples normas contradictorias entre sí no pueden ser válidas al mismo tiempo; el de claridad, toda vez que una norma que no es claramente comprensible no es válida en cuanto no puede ser propiamente normativa y asi sucesivamente. ${ }^{58}$

Por lo tanto, la dimensión racional-práctica se extiende al ámbito completo de la validez jurídica, incluida la VS, si bien de una manera más procedimental e instru-

55 Véase, en este punto, Bebhinn Donnelly, A Natural Law Approach to Normativity, AldershotEngland, Ashgate Publishing, 2007, pp. 1-4.

56 Sobre estos conceptos, véase Alberto Strumia, "Analogia”, en Diccionario interdisciplinar austral, ed. C. E. Vanney et al., en http://dia.austral.edu.ar/Analogia, fecha de consulta: de 13 de marzo de 2017.

57 Véase Rodolfo Luis Vigo, "Una teoría de la validez jurídica", en Doxa. Cuadernos de filosofia del derecho 39 (2016), pp. 99-125.

58 Véase Lon Fuller, The Morality of Law, New Haven \& London, Yale University Press, 1969, pp. 33-94. John Finnis recoje y explicita estos desiderata en Natural Law and Natural Rights, op. cit., pp. 268 y ss. 
mental (aunque no exclusivamente) que en el caso de la VR, en el que la racionalidad incluye principalmente las dimensiones sustantivas propias de la racionalidad moral. Y de aquí se sigue también otra de las debilidades del positivismo en el ámbito de la validez jurídica: la reducción de la racionalidad en el ámbito de las "fuentes sociales" a la mera articulación de datos empíricos, sin vinculación estructural con la racionalidad práctico-moral. ${ }^{59}$ Por el contrario, en la perspectiva del iusnaturalismo realista clásico, la racionalidad penetra -aunque con diversa intensidad y modalidades- la completa estructura de la validez jurídica, en todas sus dimensiones y todo su alcance.

Por otra parte, es conveniente explicitar una nueva precisión relevante, la que se refiere a la vinculación de lo que se ha venido desarrollando con la cuestión que plantea el principio lex iniusta non est lex, que se atribuye corrientemente al iusnaturalismo como tesis central. A este respecto conviene consignar, ante todo, que ese dictum de Agustín de Hipona (que en rigor, no dice exactamente eso) ${ }^{60}$ no es la tesis central del iusnaturalismo, sino la consecuencia de otras tesis, esta vez sí de carácter central, como la de la "doble validez del derecho", que hemos venido estudiando hasta ahora. Y el vínculo entre estas dos tesis radica en que resulta claro que una o unas normas carentes de validez jurídica, y que por lo tanto no generan obligaciones, también jurídicas, difícilmente pueden denominarse "derecho”, como no sea en un sentido solamente analógico, diluido y parcial.

En este punto, John Finnis ha sostenido que la fórmula lex iniusta non est lex,

... reconoce en sus palabras iniciales que lo que está en cuestión [una ley positiva injusta] es, en ciertos aspectos importantes -quizá generalmente y presuntivamente decisivos- "derecho", pero luego, en su retractación o negación de esa afirmación, sostiene que, desde que la justicia es el verdadero objetivo de tener y respetar el derecho, esta deficiencia particular del derecho respecto de la justicia lo priva del significado decisivo que todo derecho pretende tener. Por lo tanto, es derecho solo en un sentido que debe ser juzgado [...] como distorsionado y secundario y por ende no central. ${ }^{61}$

De este texto del profesor de Oxford resulta posible extraer las siguientes conclusiones, que confirman lo que se ha venido sosteniendo hasta ahora: i) que existe una validez de las normas jurídicas, de carácter genérico y presuntivo, según la cual aquello que aparece establecido autoritativamente como derecho ha de ser, prima facie, reconocido como tal y genera una obligación jurídica, también prima

59 Véase H.L.A. HART, The Concept of Law, 2 ed., Oxford, Oxford University Press, 1997, pp. 100-110.

60 Véase Agustín de Hipona, De libero arbitrio, I, 33; el texto preciso del filósofo africano es el siguiente: Nam lex nihi ese non videtur, quae iusta non fuerit. Por lo tanto, la afirmación de que lex iniusta non est lex no se encuentra en la obra de Agustín. Se cita conforme a la siguiente edición: Obras de San Agustín (Edición bilingüe). III. Obras Filosóficas, Madrid, BAC, 1982, p. 227. Véase también Carlos Ignacio MASSINI-CoRreAs, "La máxima lex iniusta non est lex y algunas opiniones contemporáneas”, en AA.VV., In umbra intelligentiae. Estudios en homenaje al Prof. Juan C. Cruz, Pamplona, EUNSA, 2011, pp. 587-604.

61 John FinNis, "Natural Law Theories", op. cit., pp. 22-23. 
facie, de respetarlo; ii) que esa validez presuntiva y prima facie resulta derrotada o anulada cuando esas normas incurren en un déficit, grave y evidente, de justicia, ya que esta justicia es la que otorga el sentido primario a la existencia misma de las normas de derecho; y iii) que por lo tanto aquellas normas, presuntamente válidas jurídicamente, que resultan derrotadas por su déficit de justicia, solo pueden ser denominadas "derecho" en un sentido defectivo, secundario y derivado.

La tercera precisión que conviene efectuar se refiere a la noción, muy debatida y difundida en los últimos años, de "derrotabilidad" de las normas jurídicas. En su breve Diccionario de teoria juridica, Brian Bix escribe que "derrotabilidad"

... se refiere a la capacidad que tiene una conclusión de ser justificada a través de ciertos criterios que son cumplidos, aunque con la posibilidad de ser "derrotada" o refutada si se cumplen otros criterios adicionales. Algunos autores (Hart [1907-1992] en particular, en algunos de sus trabajos iniciales) sostienen que la derrotabilidad de los conceptos jurídicos es importante para comprender la naturaleza del derecho. ${ }^{62}$

Esta noción de "derrotabilidad" (defeasibility), que quedaría mejor expresada con palabras castellanas como "anulabilidad" o "revocabilidad", y que en una de sus acepciones hace referencia a la aptitud que tienen las normas jurídicas de ser anuladas o revocadas por normas superiores o por principios moral-jurídicos, ${ }^{63}$ puede ser utilizada -tal como lo hace Finnis- para significar la posibilidad de invalidación de una norma jurídica, ya sea en general o en su aplicabilidad a un caso concreto, ${ }^{64}$ en razón de su injusticia grave y evidente. Dicho en otras palabras: una norma injusta resultará "derrotable" cuando su contenido conduce a resultados notoriamente injustos, y, por lo tanto, su validez formal-institucionalsocial (VS) queda anulada o revocada por un principio dotado de validez jurídicoracional-moral (VR).

Todo esto, que aparece con claridad para una aproximación iusnaturalista, ha sido objeto de arduos y alambicados debates entre los autores positivistas. Estos debates parecen tener su origen en que, desde una perspectiva estrictamente positivista, resulta dificil de explicar el fenómeno, que se presenta de hecho a la experiencia jurídica, de que ciertas normas -válidas desde el punto de vista formalinstitucional-social- se dejan de aplicar de manera efectiva en muchos casos en razón de sus resultados gravemente injustos. En efecto, si la única validez que se reconoce es la formal-institucional-social y no existen normas superiores, v. gr.

62 Brian BIX, Diccionario de teoría jurídica, México, UNAM, 2009, p. 75.

63 También se habla de derrotabilidad de las proposiciones que integran el razonamiento juridico; véase en este punto Juan Carlos BAYón, “¿Por qué es derrotable el razonamiento jurídico?”, en Doxa 24 (2001), pp. 35-62. Véase también Neil MACCormick, "Defeasibility in Law and Logic", en AA.VV., Informatics and the Foundations of Legal Reasoning, ed. Z. Bankowski et al., Dordrech-BostonLondon, Kluwer Publishing, 1995, pp. 99-117.

64 Cuando una norma que en general aparece como justa resulta radicalmente injusta en un caso concreto, el recurso a principios jurídico-morales para anularla o corregirla se ha llamado clásicamente "equidad", y ha sido estudiada por casi todos los pensadores de la tradición central de Occidente; véase Carlos Ignacio MASSINI-CORREAS, "Sobre la equidad. Consideraciones sobre un texto aristotélico”, en Sobre el realismo jurídico, Buenos Aires, Abeledo-Perrot, 1978, pp. 73-107. 
constitucionales, que justifiquen con claridad la "derrota" de una o algunas normas, este fenómeno queda sin justificación razonable y remitida al ámbito de la mera arbitrariedad. Y es por eso que los positivistas más consecuentes, como v. gr. Andrei Marmor, llevan adelante una extensa crítica contra la posibilidad misma de que normas formalmente válidas resulten derrotadas o revocadas. ${ }^{65}$

\section{MÁs SOBRE IUSNATURALisMo Y VALIDEZ: ACOTACIÓN BREVE SOBRE TOMÁS DE AQUINO}

Ahora bien, antes de pasar al desarrollo de las correspondientes conclusiones, es oportuno remitirse brevemente a algunos textos de Tomás de Aquino referidos a la problemática estudiada, con la finalidad de establecer si lo expuesto hasta ahora guarda una relación sistemática consistente con los desarrollos adelantados por el Aquinate. Y esta digresión tiene cierta relevancia toda vez que, tal como lo sostiene Mark Murphy,

... puede pensarse que para comenzar una discusión acerca de la teoría de la ley natural no hay nada mejor que estipular un significado acerca de la expresión 'teoría de la ley natural' y proceder a partir de allí. Pero hay un camino mejor, uno que toma como su punto de partida el papel central que juega la teorización moral de Tomás de Aquino en la tradición de la ley natural. Si hay alguna doctrina que sea la "teoría de la ley natural", esa es la de Tomás de Aquino. ${ }^{66}$

Por lo tanto, pareciera que si se pretende exponer una doctrina iusnaturalista de la validez jurídica, resulta inexcusable remitirse aunque sea someramente a los textos correspondientes del pensador de Aquino.

Uno de estos textos del Aquinate se encuentra en el denominado "Tratado de la Ley Antigua" de la Summa Theologiae, donde, al abordar el tema de los preceptos judiciales o jurídicos, se afirma que "los preceptos judiciales y ceremoniales [por oposición a los morales] tienen otra razón de obligar, que proviene no solo de la razón natural, sino de su simple institución". ${ }^{67}$ Por otra parte, y al tratar del poder (obligante) de las leyes positivas, Tomás de Aquino consigna que "en las cosas humanas se dice que es justo aquello que es recto según la regla de la razón. Pero la primera norma de la razón es la ley natural [...] Por lo tanto, toda ley humana [positiva] tendrá razón de ley en la medida en que se derive de la ley de la naturaleza”. ${ }^{68}$ Y después de establecer que esta derivación tiene lugar de dos modos: i) por conclusión o inferencia lógica, y ii) por determinación de lo que se encuentra indeterminado en la ley natural, el Aquinate agrega que

65 Véase Andrei MARMor, Interpretation and Legal Theory, Oxford, Clarendon Press, 1992, pp. 135-138.

66 Mark Murphy, "The natural law tradition in ethics", en Stanford Encyclopedia of Philosophy, Winter 2011 Edition, ed. Edward N. Zalta, en https://plato.stanford.edu/archives/win 2011/entries/ natural-law-ethics/

67 Tomás de Aquino, Summa Theologiae, I-II, q. 104, a. 4, ad. 2.

68 Ibid., q. 95, a. 2. 
... los preceptos que se derivan del primer modo, si bien forman parte de la ley humana positiva, tienen vigor no solo por ser leyes humanas sino por tener algún vigor de la ley natural. Y los preceptos que se derivan del segundo modo tienen vigor solo de su pertenencia a la ley humana. ${ }^{69}$

Y más adelante, hablando del poder (obligatorio) de las leyes positivas, escribe que "las leyes humanas o son justas o son injustas", con lo que contradice claramente a aquellos autores que le endilgan la tesis según la cual las leyes injustas no serian leyes en absoluto; además, agrega que "si son justas [las leyes] tienen el poder de obligar en el foro de la conciencia”, y precisa que las leyes son justas "por razón del fin, cuando se ordenan al bien común; por razón de su autor, cuando la ley establecida no excede las atribuciones del legislador; y por razón de la forma, cuando se imponen las cargas a los súbditos con igualdad de proporción y en orden al bien común". ${ }^{70}$

Y finalmente, ya más adelante, en el llamado "Tratado de la justicia”, el Aquinate afirma que

... algo es justo de dos maneras, o bien por la misma naturaleza de las cosas y en este caso se llama derecho natural, o bien por cierta convención entre los hombres, y entonces se denomina derecho positivo [...] Ahora bien, las leyes se escriben para la declaración de uno y otro derecho [...] pero la ley escrita contiene el derecho natural, pero no lo instituye, ya que este toma su vigor (robur) no de la ley escrita, sino de la naturaleza. Pero el derecho positivo se contiene e instituye por la ley escrita, dándole esta su vigor (robur) y autoridad..$^{71}$

De la lectura y el análisis de estos textos seleccionados es posible extraer algunas conclusiones explicativas y de precisión, en especial las siguientes: i) ante todo, corresponde aclarar que si bien Tomás de Aquino usa la palabra validus ocho veces en su toda su obra, de la lectura de los lugares en que la usa, realizada a través el Index Thomisticus de Robertus Busa, surge con claridad que no lo hace nunca en relación con las normas jurídicas o morales, es decir, en el sentido de "validez" o "válido" en el ámbito jurídico ${ }^{72}$; ii) en este ámbito, el Aquinate utiliza más bien la palabra "justo", o bien expresiones tales como "razón de obligar", "vigor" (vigoris, vim, robur), o "razón de ley" para referirse a lo que justifica la obligatoriedad de las normas, en especial las jurídicas; esto significa que para él lo que justifica lo que llamaríamos hoy "fuerza deóntica" de las normas jurídicas es una cierta cualidad de estas proposiciones normativas que él designa principalmente con las palabras "justo" o "justicia”; iii) para Tomás de Aquino, esta justicia-cualidad valiosa de las normas se integra con tres dimensiones: ordenación al bien común político, autoridad y competencia del emisor-fuente y proporcionalidad en los

\footnotetext{
69 Ibid.

$70 \quad$ Ibid., q. 96 , a. 4.

71 Ibid., II-II, q. 60. a. 5.

72 Corpus Thomisticum-Index Thomisticus, by Robertus Busa and associates, edition web por Eduardo Bernot y Enrique Alarcón, Fecha de consulta: 10 de marzo de 2017.
} 
repartos de bienes y cargas $^{73}$; iv) estas tres características pueden ser reducidas a dos exigencias principales: a) la exigencia institucional-social de que el emisor de la norma tenga autoridad y resulte competente para la formulación de esa norma; y b) la exigencia valorativo-moral de que la norma resulte justa, tanto por su ordenación al bien común (justicia general), cuanto por la coordinación y distribución proporcionada de lo que se atribuye en vistas al bien común (justicia distributiva); v) respecto de esta última exigencia, Budziszewski comenta que el Aquinate "nos invita a considerar cuál cercanamente está vinculada la causa final de la ley, el bien común, con su causa formal, la ecuanimidad de proporción. Cualquiera que piense que las exigencias del bien común pueden justificar una norma desproporcionada, está entendiendo mal el sentido del bien común". ${ }^{74}$

Ahora bien, si lo precisado en los puntos anteriores se vincula con un texto expreso de Tomás de Aquino, en especial el primero de los citados, en el que se sostiene que la razón de obligar de las normas jurídicas proviene ya sea mediatamente de la razón práctico-moral, ya sea inmediatamente de su institución por la autoridad legitima, queda en evidencia que para el Aquinate existe -poniéndolo en la terminología actual- tanto una validez jurídica formal-institucional, cuanto otra de carácter material-moral. Esta doble validez, si es expresada en un contexto discursivo iusnaturalista, puede enunciarse diciendo que la validez jurídica puede ser o bien natural (justificada por su adecuación a las exigencias racional-prácticas), o bien positiva (justificada por su fuente en una autoridad legitima). Pero, además, es preciso tener en cuenta que, tal como lo expresa el pensador italiano en otro de los textos citados, ambas formas de validez se refieren a la ley positiva, ya que "las leyes se escriben para la declaración de uno y otro derecho". ${ }^{75}$

En definitiva, es posible concluir que, con un lenguaje diverso propio de la época en que fue formulado, Tomás de Aquino reconoce y desarrolla la tesis aquí expuesta de la doble validez del derecho, que no remite a una división tajante entre dos formas contrarias de validez, sino a un continuum que va desde la justificación racional-moral a la formal-social (en el orden de la fundamentación), y desde la formal-social a la racional (en el orden del conocimiento y de la manifestación). Pero esta continuidad hace que la validez formal-social esté también transida de una racionalidad no meramente instrumental, así como que la validez racionalmoral tenga también una manifestación social. François Daguet, en un importante volumen sobre el pensamiento político-jurídico del Aquinate, sostiene en este último sentido que

... según el grado de contingencia presente en cada caso, la ley civil derivará de modo más o menos próximo de los primeros principios de la ley natural. Un edificio legislativo es, de este modo y en principio, una cadena continua de derivaon Law, New York, Cambridge University Press, 2014, pp. 384 y ss.

74 Ibid., p. 384.

75 Véase nota 63. 
ciones a partir de primeros principios que, en la práctica, pueden quizá parecer muy lejanos. ${ }^{76}$

Esta interpretación del pensamiento de Aquino acerca de la validez del derecho no es, por supuesto, unánime; no es aceptada por varios autores, en especial aquellos incluidos en lo que puede denominarse escuela "finnisiana del derecho natural"; entre estos conviene destacar a Maris Köpcke quien, en un valioso trabajo con el escueto título de "Validez", afirma que:

... la posición que sostiene que el valor moral es condición necesaria de la validez se ha atribuido erróneamente a la escuela clásica del derecho natural. El origen del error quizá sea una lectura equivocada, sacada de contexto, del adagio de Tomás de Aquino "lex injusta non es lex" [...] El argumento es que es útil distinguir dos sentidos de "derecho". Un sentido es el de la validez del derecho considerado válido en un ordenamiento dado. En este sentido, una regla no deja [de ser] jurídica por el mero hecho de ser inmoral: el valor moral no afecta a la validez. ${ }^{77}$

Pero de inmediato, Köpcke sostiene que puede hablarse de "derecho" en un sentido más rico, según el cual el propósito o la razón central del derecho es promover el bien común y, por ello, el derecho moralmente valioso es más propiamente derecho que el derecho injusto y, en este sentido, "una ley (válida en un ordenamiento) injusta no es propiamente una ley (no cumple con la razón de ser del derecho)" ${ }^{78}$ De este modo existiría un derecho válido -en un sentido meramente positivo- que no cumpliría con la razón de ser del derecho. Tal como se desprende de lo desarrollado en los párrafos anteriores, esta separación entre "validez" y "razón de ser" del derecho no aparecería como propia del iusnaturalismo clásico, tema sobre el cual el autor de este trabajo tiene la intención de explayarse en un texto ulterior.

\section{CONCLUSIONES SUMARIAS}

En definitiva, luego de los desarrollos precedentes es posible sostener que, desde una perspectiva iusnaturalista, es imprescindible distinguir en el universo jurídico-normativo dos formas de validez de las normas: i) la formal-institucionalsocial, centrada en la genealogía o el linaje de esas normas, es decir, en su generación a través de las denominadas "fuentes sociales", que reviste un carácter prima facie o presuntivo, y que por lo tanto otorga a las normas correspondientes una validez "derrotable" en caso de que estas incurran en injusticia grave y evidente; y ii) la validez material-racional-moral, según la cual las normas jurídicas son válidas $\mathrm{y}$, por ende, obligatorias en razón de su servicio de justicia al bien

76 François Daguet, Du politique cez Thomas D'Aquin, Paris, Librairie Philosophique J. Vrin, 2015, p. 238. Véase también Robert P. George, "Natural law and positive law", en In Defense of Natural Law, Oxford, Oxford University Press, 2001, pp. 107-110.

77 Maris Köpcke Tinturé, "Validez”, en Jorge Fabra Zamora y Verónica Rodríguez Blanco, Enciclopedia de filosofia y teoría del derecho, vol. II, México, UNAM, 2015, p. 955.

78 Ibid., p. 956. 
humano común, validez que desaparece cuando una o varias normas jurídicas formalmente válidas incurren en una injusticia notoria y "extrema", para utilizar una palabra cara a Robert Alexy. ${ }^{79}$

De este modo, la noción de "validez jurídica" queda explicitada en su múltiple significación analógica, en la que es necesario distinguir dos acepciones principales: una referida a su determinación y manifestación externo-social de las normas, y la otra a su consistencia racional-valorativa interna. Ahora bien, si la cuestión de la validez se aborda desde la perspectiva propiamente práctica, es decir, directiva de la conducta humana, que es la propia de los saberes jurídicos, resulta manifiesto que lo que en definitiva interesa es que esa dirección sea recta, lo que en el caso de la conducta jurídica significa que ella sea justa, es decir, se ordene al bien humano común de la comunidad completa. Y es precisamente esa ordenación la que da sentido a la sanción institucional-social de las normas jurídicas, sanción que es instrumental al servicio de esa ordenación justa, y por ello se subordina en definitiva al criterio valorativo de contenido: el de la justicia de la dirección y coordinación de la conducta en la sociedad politica.

Finalmente, corresponde consignar que esta tesis de la "doble validez del derecho" explica de un modo satisfactorio un dato inexcusable de la experiencia jurídica: que los sujetos de derecho y los operadores jurídicos -y esto resulta en especial relevante- distinguen con claridad entre la obligatoriedad que generan las normas por su establecimiento en las fuentes sociales y la que deviene de su contenido moralmente justo. Robert Spaemann sostiene sobre esto que nada

\footnotetext{
... ha podido cambiar hasta ahora el hecho que sirve de base a la idea de derecho natural: los hombres distinguen acciones justas o injustas. $\mathrm{Y}$ el criterio último de esta distinción no es la adecuación de las acciones a las leyes positivas existentes, pues estos mismos hombres distinguen también leyes justas e injustas, sentencia justas e injustas. ${ }^{80}$
}

Y este fenómeno social, experiencialmente perceptible, solo se explica si se sostiene la tesis de la doble validez del derecho, desarrollada por la tradición iusnaturalista en los más de veinticinco siglos de su trayectoria en la sabiduria humana.

\section{BIBLIOGRAFÍA}

АввÀ, Giuseppe, Quale impostazione per la filosofia morale?, Roma, LAS, 1996.

Agazzi, Evandro, "Analogicità del concetto di scienza. Il problema del rigore e dell'oggettività nelle scienze humane", en AA.VV., Epistemologia e scienze umane, ed. V. Possenti, Milano, Massimo, 1979, pp. 57-95.

79 Robert AlEXY, El concepto y la naturaleza del derecho, Madrid, Marcial Pons, 2008, pp. 69 y passim.

80 Robert Spaemann, "La actualidad del derecho natural", en Crítica de las utopías politicas, Pamplona, EUNSA, 1980, p. 315. 
Alexy, Robert, El concepto y la validez del derecho, Barcelona, Gedisa, 1997.

AleXY, Robert, El concepto y la naturaleza del derecho, Madrid, Marcial Pons, 2008.

Aguino, Tomás de, Summa Theologiae, I-II, q. 104, a. 4, ad. 2.

Aguino, Tomás de, Summa Theologiae, II-II, q. 60, ad. 5.

Audi, Robert, Reasons, Rights, and Values, Cambridge, Cambridge University Press, 2015.

Bayón, Juan Carlos, “¿Por qué es derrotable el razonamiento jurídico?”, en Doxa. Cuadernos de filosofia del derecho 24 (2001), pp. 35-62. DOI: 10.14198/ DOXA2001.24.02

Bıx, Brian, Diccionario de Teoría Jurídica, México D.F., UNAM, 2009.

Bochenski, Józef Maria, Los métodos actuales del pensamiento, Madrid, Rialp, 1979.

Budziszewski, Jay, Commentary on Thomas Aquinas's Treatise on Law, New York, Cambridge University Press, 2014.

Buligyn, Eugenio, El positivismo jurídico, México, Fontamara, 2006.

Corominas, Joan, Diccionario etimológico de la lengua castellana, Madrid, Gredos, 1976.

Corpus Thomisticum-Index Thomisticus. Edición web por Eduardo Bernot y Enrique Alarcón, http://www.corpusthomisticum.org/it/index.age fecha de consulta: 10 de marzo de 2017.

CоттA, Sergio, Giustificazione e obligatorietà delle norme, Milano, Giufrè Editore, 1981.

Daguet, François, Du politique cez Thomas D'Aquin, Paris, Librairie Philosophique J. Vrin, 2015.

De VRies, Jan, Voz "Validez", en Diccionario de Filosofia, dir. W. Brugger, Barcelona, Herder, 1975, pp. 523-524.

Donnelly, Bebhinn, A Natural Law Approach to Normativity, Aldershot-England, Ashgate Publishing, 2007.

Etcheverry, J. B. y P. Serna (eds.), El caballo de Troya del positivismo jurídico. Estudios críticos sobre el Inclusive Legal Positivism, Granada, Comares, 2010.

Ferrater Mora, José, Diccionario de Filosofia, Madrid, Alianza, 1979.

Finnis, John, "Introduction”, en Collected Essays. Vol. IV. Philosophy of Law, Oxford, Oxford University Press, 2011.

FinNis, John, "Law as Coordination”, en Collected Essays. Vol. IV. Philosophy of Law, Oxford, Oxford University Press, 2011.

FinNIS, John, "Natural law theories", en Edward N. Zalta (ed.), Stanford Ecyclopedia of Philosophy, 2011, http://plato.stanford.edu/entries/natural-law-theories /

FinNIs, John, Natural Law and Natural Rights, Oxford, Oxford University Press, 2011. 
Fuller, Lon, The Morality of Law, New Haven \& London, Yale University Press, 1969.

Gardner, John, "Legal Positivism: 5 1/2 Myths", en American Journal of Jurisprudence 46 (1) (2001), pp. 199-227. DOI: 10.1093/ajj/46.1.199

Garzón VAldÉs, Ernesto, Derecho y "naturaleza de las cosas". Análisis de una nueva versión del derecho natural en el pensamiento jurídico alemán contemporáneo, Vol. II, Córdoba-Argentina, Universidad Nacional de Córdoba, 1971.

George, Robert P., "Natural law and positive law", en In Defense of Natural Law, Oxford, Oxford University Press, 2001, pp. 107-110. DOI: 10.1093/acprof:o so/9780198267904.003.0011

GiLson, Étienne, La unidad de la experiencia filosófica, Madrid, Rialp, 2004.

Graneris, Giuseppe, La filosofia del diritto nella sua storia e nei suoi problemi, Roma-Paris-Tournai-New York, Desclée, 1961.

Habermas, Jürgen, Facticidad y validez, Madrid, Trotta, 1998.

HART, Herbert Lionel Adolphus, The Concept of Law, 2a ed., Oxford, Oxford University Press, 1997.

Hudson, William D. (ed.), The Is-Ought Question, London, MacMillan, 1969.

InCIARTE, Fernando, Eindeutigkeit und Variation. Phänomene und das Problem des Reduktionismus, Freiburg, Alber, 1973.

InGARDEn, Roman, Sobre la responsabilidad. Sus fundamentos ónticos, trad. J. M. Palacios, Madrid, Caparrós, 2001.

Kalinowski, Georges, "Essai sur le caractère ontique du droit. Contribution à l'être intentionnel et à l'ontologie du droit”, en Revue de l'Université d'Otawa V-34 (1964), pp. 81-99.

KaLINowski, Georges, Initiation à la philosophie morale, Paris, Societé d'Éditions Internationales, 1966.

Kalinowski, Georges, Logique des normes, Paris, PUF, 1972.

Kalinowski, Georges, Lógica del discurso normativo, Madrid, Tecnos, 1975.

Kalinowski, Georges, La logique déductive. Essai de présentation aux juristes, Paris, PUF, 1996.

Kelsen, Hans, Teoría pura del derecho, México, Porrúa.

KöPCKE TinturÉ, Maris, "Validez", en Jorge FABRA ZAMORA y Verónica Rodríguez Blanco, Enciclopedia de filosofia y teoría del derecho, Vol. II, México, UNAM, 2015.

Llano, Alejandro, Teoría del conocimiento, Madrid, BAC, 2015.

MacCormick, Neil, "Defeasibility in law and logic”, en Z. Bankowski et al. (eds.), Informatics and the Foundations of Legal Reasoning, Dordrech-Boston-London, Kluwer Publishing, 1995, pp. 99-117. 
MARMOR, Andrei, Interpretation and Legal Theory, Oxford, Clarendon Press, 1992.

Marmor, Andrei, Philosophy of Law, Princeton and Oxford, Princeton University Press, 2011.

MARMor, Andrei y Sarch, A., "The Nature of Law", en Edward N. Zalta (ed.), Stanford Encyclopedia of Philosophy, 2015, https://plato.stanford.edu/archives/ fall2015/entries/lawphil-nature/

Massini-Correas, Carlos Ignacio, "Sobre la equidad. Consideraciones sobre un texto aristotélico", en Sobre el realismo jurídico, Buenos Aires, Abeledo-Perrot, 1978, pp. 73-107.

MASSINI-Correas, Carlos Ignacio, La falacia de la "falacia naturalista", MendozaArgentina, Edium, 1995.

Massini-Correas, Carlos Ignacio, Filosofia del Derecho. Vol. I, El derecho, los derechos humanos y el derecho natural, Buenos Aires, LexisNexis/Abeledo Perrot, 2005.

Massini-Correas, Carlos Ignacio, Filosofia del Derecho. Vol. III, El conocimiento y la interpretación jurídica, Buenos Aires, Abeledo-Perrot, 2008.

MASSINI-CoRreas, Carlos Ignacio, "Sobre ciencia práctica y prudentia. Aproximaciones desde las ideas de John Finnis”, en Sapientia 227-228 (2010), pp. 41-53. En http://bibliotecadigital.uca.edu.ar/repositorio/revistas/sobre-cienciapractica-prudentia-aproximaciones.pdf

MASSINI-CoRreas, Carlos Ignacio, "La máxima 'lex injusta non est lex' y algunas opiniones contemporáneas”, en A. L. González y M. I. Zorroza (eds.), In umbra intelligentiae. Estudios en homenaje al Prof. Juan Cruz Cruz, Pamplona, Eunsa, 2011, pp. 587-604.

MASSINI-CoRreas, Carlos Ignacio, "Entre reductivismo y analogia. Sobre el punto de partida de la filosofia del derecho", en Persona y Derecho 66-67 (2012), pp. 353-385. En https://www.unav.edu/publicaciones/revistas/index.php/ persona-y-derecho/article/view/3129

MASSINI-CORREAS, Carlos Ignacio, "Riduzionismo, fatti sociali e normatività del diritto", en Rivista di filosofia del diritto 1 (2013), pp. 227-244. DOI: 10.4477/73549

Massini-Correas, Carlos Ignacio, Facticidad y razón en el Derecho. Análisis crítico de la iusfilosofia contemporánea, Buenos Aires, Marcial Pons, 2015.

McInerny, Ralph, Aquinas and Analogy, Washington D.C., The Catholic University of America Press, 1996.

Millán-Puelles, Antonio, Teoría del objeto puro, Madrid, Rialp, 1990.

Murphy, Mark, Philosophy of Law. The Fundamentals, Oxford-Malden-Carlton, Blackwell, 2007.

MurPHy, Mark, "The Natural Law Tradition in Ethics", en Edward N. Zalta (ed.), Stanford Encyclopedia of Philosophy, 2011. En https://plato.stanford.edu/ archives/win 2011/entries/natural-law-ethics/ 
PicAVEt, Emmanuel, Kelsen et Hart. La norme et la conduite, Paris, PUF, 2000.

RAz, Joseph, "Legal validity", en The Authority of Law. Essays on Law and Morality, Oxford, Clarendon Press, 1997, pp. 146-149.

RAz, Joseph, "Legitimate authority", en The Authority of Law. Essays on Law and Morality, Oxford, Clarendon Press, 1997, 3-27.

San Agustín, Obras de San Agustín (Edición bilingüe), vol. III, Obras filosóficas, Madrid, BAC, 1982.

SERna, Pedro, Filosofia del derecho y paradigmas epistemológicos, México D. F., Porrúa, 2006.

Simon, Yves, Practical Knowledge, New York, Fordham University Press, 1991.

SoAJE Ramos, Guido, "Sobre derecho y derecho natural. Algunas observaciones epistemo-metodológicas”, en Ethos 6/7 (1979). En http://www.infip.org.ar/ wp-content/uploads/2015/08/Soaje-Ramos-SOBRE-DERECHO-Y-DERECHO-NATURAL.pdf

Spaemann, Robert, "La actualidad del derecho natural", en Crítica de las utopías politicas, Pamplona, Eunsa, 1980.

Strumia, Alberto, “Analogia”, en Diccionario Interdisciplinar Austral, http://dia. austral.edu.ar/Analogía

VIGo, Rodolfo Luis, "Una teoría de la validez jurídica", en Doxa. Cuadernos de filosofia del derecho 39 (2016), pp. 99-125. DOI: 10.14198/DOXA2016.39.07 